Enhancing Parent-Child Book Reading in a Disadvantaged Community

\author{
Gordon Elias ${ }^{1}$, Ian Hay ${ }^{2}$, Ross Homel, ${ }^{1}$ and Kate Freiberg ${ }^{1}$ \\ ${ }^{1}$ Griffith University \\ ${ }^{2}$ The University of Queensland
}

Published in:

The Australian Journal of Early Childhood, 31, 2006, pp. 20-25

This research was funded from an ARC research grant to Ross Homel, Gordon Elias and Ian Hay as the chief investigators with Mission Australia as the industry partner. The co-operation of Education Queensland is acknowledged, particularly that of Carmel Prothero and Ruth Ernst, the two developmental language teachers involved with this project.

Address for correspondence Dr Gordon Elias, School of Cognition, Language and special education, Griffith University, Nathan, Brisbane, 4111 G.Elias@griffith.edu.au

Assoc Professor Ian Hay School of Education, The University of Queensland, St Lucia, Qld, 4072. I.Hay@uq.edu.au 
Parent-child book reading 2

Enhancing Parent-Child Book Reading in a Disadvantaged Community 


\begin{abstract}
A parent-child dialogic reading program was implemented across four preschools involving 62 caregivers/parents in a low socioeconomic status, disadvantaged community, where English was not the first language in 54\% of the homes. The program aimed to enhance children's language and emergent literacy development, and increase parental involvement in their preschoolers' education. Over the 6 months of the program, the amount of child-parent reading more than doubled, from an average of 38 minutes of parent-child reading per week, to 89 minutes of parentchild reading per week. Year one teachers in the following year reported positively on the children's literacy readiness, compared to that of previous intakes. The program is described in the paper.
\end{abstract}


There is a growing consensus that appropriate early learning experiences can act as protective factors, with positive effects upon the cognitive and social development of children to allay serious educational and behaviour problems (Bishop \& Leonard, 2000; Homel, Elias, \& Hay, 2001). Further to this is the belief that positive family and parental practices can facilitate a child's language development (Marvin \& Wright, 1997; Whitehurst \& Lonigan, 1988) and literacy development (FieldingBarnsley \& Purdie, 2003; Wasik, Bond, \& Hindman, 2002). In this article we describe a parent-child book reading program developed for four urban preschools in a low socioeconomic status, disadvantaged, and culturally diverse community.

\section{Engaging parents}

Hoover-Dempsey and Sandler (1997) proposed that three major constructs are central to understanding why parents become involved in their children's education: their role construction; their sense of efficacy; and the invitations and opportunities for participation extended to them. For these authors, role construction entails the expectations of parents and others regarding appropriate school-related behaviours on their part, as well as the behaviours that the parents and others actually enact. As research has shown, many parents believe that the educational decisions affecting their children are, by and large, the responsibility of the school and that they have no active role (Hanafin \& Lynch, 2002), while others believe that they should have a considerable degree of control over these decisions. Secondly, allied to parents' construction of their role in their children's education are their perceptions of their own ability to assist their children to succeed in school. According to efficacy theory, parents with a high sense of efficacy in this domain are more likely to choose to become involved in their children's education compared with those who view themselves as less capable (Bandura, 1997).

Hoover-Dempsey and Sandler's third major construct influencing parents' involvement in their children's education includes such practices as invitations from the school to become involved. Although these activities may constitute bona fide attempts on the part of teachers and schools to involve parents in authentic ways in children's education, many parents perceive themselves to be excluded from genuine participation in the educational process. Hanafin and Lynch (2002) reported that parents in their study felt unwelcome on school premises, suffering feelings of anxiety 
and nervousness which "led to a significant undermining of their consultative possibilities with classroom teachers regarding their children” (p. 46). Similarly, as Hoover-Dempsey and Sandler (1997) pointed out, parents are most likely to choose to become involved in their children's education when their role construction verifies the importance of involvement, when they have a high sense of efficacy, and when they perceive the demands and invitations for involvement as authentic.

\section{Emergent literacy}

It is widely accepted that preschool children have learnt much that is important about literacy before formal reading instruction begins (Bishop \& Leonard, 2000; Snow, Burns \& Griffin, 1998; Teal \& Sulzby, 1986). Certainly, the frequency and quality of parent-child reading is an important determinant of children's later literacy attainment (Elley, 1989). In their review of children's acquisition of literacy, Whitehurst and Lonigan (1998) proposed that there should be a continuation between the prereading behaviours of very young children, and the reading skills the children later acquire more formally in the primary and middle school settings. These skills are conceptualised as falling along the same developmental continuum. Accordingly, these authors support the concept of emergent literacy (Teale \& Sulzby, 1986) to refer to "the skills, knowledge and attitudes that are presumed to be developmental precursors to conventional forms of reading and the environments that support these developments” (p. 849).

Importantly, Whitehurst et al. (1994) taught mothers specific interactive techniques to use when reading picture books with their preschool age children. This intervention program, called dialogic reading, produced substantial effects on preschool children's language development. Dialogic reading involves families and parents reading with their children, rather than, to their children or correcting their child’s reading (Arnold, Lonigan, Whitehurst, \& Epstein, 1994; Hargrave \& Sénéchal, 2000; Morgan \& Goldstein, 2004). The implication of the dialogic reading research is that caregivers in low socioeconomic status communities can be encouraged to use the types of language that should help prepare their children for the language demands of the classroom. It is the content of talk and the dyadic interaction during storybook reading time that is the critical issue. Parents are asked to engage in dialogue with their child about the content and context of the story and allow the child to direct and 
share in the conversations associated with the text and pictures. The caregiver expands on the child's dialogue, and the evidence is that the child then practices this linguistically enhanced dialogue. Thus, the child improves in vocabulary, syntax, and semantic knowledge, as well as in the social skills of turn taking, and the conventions associated with reading text (pragmatics). In time, the child will be able to read along and direct the caregiver in re-reading familiar text, but this is secondary to the dyadic interaction. For the child, dialogic reading helps to connect reading with positive parental social interactions and attention; for the caregiver, it facilitates confidence and involvement in the child's reading acquisition process (Morgan \& Goldstein, 2004; Whitehurst et al., 1994).

Notably, the results of the Bus, van Ijzendoorn, and Pellegrini's (1995) metaanalysis on the intergenerational transmission of literacy identified that parentpreschooler book reading was a pivotal environmental factor for readiness for and success with reading. These investigators found that the frequency of book reading to preschool children affected the children's language growth, emergent literacy, and reading achievement. Further, Craig-Thoreson and Dale (1999) suggested that shared book reading is an ideal context for the development of children's language skills because it provides opportunities for the development of new concepts, opportunities for the adult to monitor children's comprehension through questioning, and occasions for the development of vocabulary, language forms and functions, as adults and children negotiate meaning together. In this regard, Kim and Cole (2002) identified that mothers tended to utilize more language "instructional strategies" during picture book reading than in other interaction situations.

Importantly, a number of studies have noted marked social class differences in parent-child involvement in experiences that facilitate the emergence of the child's literacy (Raz \& Bryant, 1990). Teale and Sulzby (1986), for example, reported that book reading occurred as seldom as five times per year in some low-income families. As others have pointed out (Whitehurst et al., 1994; Wasik et al., 2002; Snow et al., 1998), such findings have underpinned the need for the development of literacy programs that aim to encourage parent-preschooler book reading in communities of low socioeconomic status, particularly with families where English proficiency is an issue. The indications are that children with language delays are less likely than other 
children to listen to stories, engage in dialogue with adults about books being read, or to ask or answer questions about past and future events in stories. Also, they are less likely to have adults point to words or letters in books or have words spelled for them during their writing activities at home, or have adults provide commentary when the children are watching television (Neuman \& Celano, 2001; Marvin \& Wright, 1997). The research question under investigation was whether the parent-child dialogic reading program developed to meet the perceived needs of the parents and children in this low socioeconomic disadvantaged community was effective?

\section{Target community and participants}

Recent, Australian census data on the targeted community indicated high levels of social and economic disadvantage including: lower than average median weekly household income (\$400-499 vs. \$800-899 for the wider Brisbane area); low rates of high school completion within the adult population (less than 24\% vs. 43\%); higher than average rates of single parent families (33.1\% vs. 15.7\%), unemployment (20\% vs. 7\%) and public housing (39.1\% vs. 4.3\%). Although the language of instruction in the four preschools was English, 54\% of the children were from homes where English was not the first language. The ethnic background of the preschoolers was: 42\% Caucasian; 4\% Indigenous; 32\% Vietnamese; 16\%; Pacific Islanders; and 6\% Middle East, African, or Chinese. Based on pre-intervention language data from this group of children $(N=157)$, Hay et al. (2003) reported that $38 \%$ of children commenced Year one with at least a twelve month delay in receptive language age test scores, and 19\% had at least a twelve month delay in expressive language age test scores. Reporting on one of the four local primary schools involved in the present study, Anderson (2002) noted that 63\% of the students performed below their chronological age on one or more literacy measures in their early years of schooling.

In past years, teachers at the preschools had expressed concern that many of the parents of the children had shown reluctance to become involved in their children's education. In spite of invitations to attend activities and functions at the preschool, they had rarely participated. For example, few parents attended meetings at the preschool that addressed such issues as "How to help your child at school". They appeared to view their role as "getting them (the children) to school on time-but (they) 
did not believe that their roles in children's education extended far beyond these basic preparations” (Hoover-Dempsey \& Sandler, 1997, p. 15, parentheses added).

\section{Procedure}

This intervention was undertaken by two experienced teachers with training in early language development who were employed fulltime by the Queensland education authority to work with the preschool and primary schools in the target community. Permission to conduct the study was given by the relevant authorities and children's permission to participate provided by their parents-caregivers. Information on the program, permission forms, and an invitation to be involved with the program was, if necessary, translated into the families' home language. Teacher aides fluent in the families' home language, the regular preschool teachers, and the visiting specialist language teachers, explained the program further to the parents at a number of social "afternoon tea” functions.

All children in the four preschools ( $N=206,49.5 \%$ girls) were screened using the Preschool Language Assessment Instrument PLAI (Blank, Rose, \& Berlin, 1978). This test measures the language demands placed on the child by the teaching-learning situation. These demands can be understood as involving four different levels of abstraction. For example, at the lowest level the child is required to respond to language concerning low-level salient perceptions (e.g., answering to the question, what is this?). At the higher levels of abstraction, language demands involve reflecting upon or restructuring perceptions (e.g., the question, what do you think will happen if ?). Children who linguistically performed at the lowest two PLAI levels were targeted for the intervention ( $N=68,53 \%$ boys), and 62 parents agreed to participate in short pre- and post-intervention interviews. Of these 62 caregivers, the majority were mothers, but interview data also reported that fathers and other family members became involved with the parent-child reading program.

\section{Intervention}

The parent-child book reading program was integrated into the regular preschool program and formed one important component of a more extensive preschool language program implemented by teachers with training in early language development. The total program focused on such aspects as vocabulary development, 
the use of abstract language and concept development. A major focus of this research was to develop socially and culturally relevant reading materials that: (a) would encourage parents and children to engage in shared book experiences; and (b) would assist parents to develop the belief that they could contribute in meaningful ways to their children's formal education. By adopting this approach, it was hoped to capitalise on the different strengths and literacy practices of the families and to avoid possible problems arising from a clash between "Western middle-class" literacy practices and the families’ models of literacy and how it develops (Auerbach, 1989; Newman \& Celano, 2001).

\section{Engaging text program}

To make books meaningful and engaging to the children and their parents, books were created for each child that was based on the child's own experiences. This was achieved by using a digital camera to take photographs of the child during various activities (at school and during other educational activities) and the photographs were then printed on A4 sized paper and compiled into personal books of a few pages. Parents as well as teachers were involved in photographing the children. That is, the content of the picture books gave children opportunities to engage in dialogue with their parents about real and meaningful experiences in the children's lives. After printing the children's Sports Day photographs, for example, parents were invited to collaborate with their child to create written text to accompany the pictures. The text could be written in English or the child's home language and, if the parent wished, text written in the child's home language had the English translation written below. Parents were encouraged to use the child's home language when creating text since it has been shown that mastery of the child's first language is a good predictor of later literacy for bilingual children (Teale \& Sulzby, 1986). This approach is similar to that used in the Pajero Valley project with Spanish-speaking parents and their children (Auerbach, 1989). Creating written text engaged the parents in high levels of dialogue with their children and provided the child with meaningful experiences relating to the conventions and functions of print and the relationships between oral and written language (Marvin \& Wright, 1997). The books were regularly taken home by the children to be read with their parents and provided a meaningful resource for the literacy activities and practices for the family. 
Purposely, the text written to accompany the pictures was short (perhaps a few words or a sentence). One reason for the brevity of the text was that, as Sénéchal et al. (1995) pointed out, less text leads to higher levels of parent-child dialogue than when large amounts of text are used (with consequential benefits for language gains and later reading achievement). Furthermore, it has been proposed that the use of books with little or no text "may be of value to practitioners who work with parents with culturally unique linguistic skills or who work with parents who have very low literacy levels” (Sénéchal et al., 1995, p. 335).

When the parents' level of language proficiency precluded their writing the negotiated text in English, they were encouraged to write the text in their home language. The use of the home language enabled the parents to play as effective a role as the English-speaking parents, and served to maintain the status of the home language in the children's eyes. If the child perceives the home language to be less prestigious than the language being taught in the formal context, there is a danger of the loss or regression of the first language or dialect (Schiff-Myers et al., 1993). Although the caregivers were encouraged to borrow books for shared reading with their children from the school and local library collections these were, largely, socially and culturally inappropriate in regard to the children's day-to-day lives (and rarely accessed).,The preschool-developed individualised picture readers were conceptualised as the catalyst for dialogic reading experiences..

\section{Outcomes}

The study started in June and finished in November of the same preschool year. A survey of 62 participating caregivers revealed that before the intervention, $29 \%$ of the parents read to their child at least once a day, for at least 15 minutes and 53\% of the parents read at least once a week for at least 15 minutes with Eighteen percent of parents reported doing no reading with their child each week. For the group, 2385 minutes of reading was occurring per week, an average of 38 minutes of parent-child reading.

At the end the intervention, $41 \%$, of the parents read to their child at least once a day, for at least 25 minutes and 59\% of the parents read at least once a week for at least 30 minutes. At this point, all 62 caregivers were reading regularly with the 
children. For the group, 5545 minutes of reading now occurred per week, an average of 89 minutes of parent-child reading. This represented a doubling of the amount of time spent in child-parent reading.

The parents were also encouraged to visit the preschools and engage in parentchild reading in this setting. Reports from parents and teachers noted that the children were highly motivated to spend more time in literacy related activities and to use more complex language when these books were used, rather than others. Significantly, according to preschool teacher reports, the non-English speaking parents showed higher levels of confidence when using these books to read with their children.

\section{Discussion of findings}

The findings from this study are comparable to those of Fielding-Barnsley and Purdie (2003) who also carried out intervention with Queensland preschool children and their parents using a form of dialogic shaped reading. In the Fielding-Barnsley and Purdie study, the amount of parent-child reading increased and this was associated with gains on literacy measures.

In the present intervention, the focus was on designing reading material that was culturally appropriate and engaging for the families so that it encouraged the parents to become involved in dialogic reading with their children. By using motivating material, the claim is that the intervention is more sustainable. This intervention provided a supportive learning environment that facilitated children's use of vocabulary and complex language structures. It also provided an opportunity to extend parents' beliefs about what they might do to influence their children's education in positive ways, and to enhance parents' perceptions of their ability to help their children succeed in school.

Interviews with the Year one teachers in the following year reported that the cohort of children involved in the home language, picture book reading program showed greater confidence with books, were more familiar with the concept of print tasks, and demonstrated greater vocabulary knowledge than previous cohorts of Year one students. The Year one teachers also reported that the children's parents were 
keener to assist with reading homework tasks, visited the Year one classrooms more, and talked with the teachers more, compared with parents of the previous year. Such findings lend support to the claim that the language discourse associated with book reading creates opportunities for children to extend and enhance their language and literacy skills, and when dialogic reading is practised both in the home and in the school, young children's language and early literacy can be improved.

\section{References}

Auerbach, E. (1989). Towards a socio-contextual approach to family literacy. Harvard Educational Review, 59, 165-181.

Anderson, S. (2002). Whole school achievement results for 2002 (school report in a disadvantaged community). Education Queensland.

Arnold, D.S., Lonigan, C.J., Whitehurst, G.J., \& Epstein, J.N. (1994). Accelerating language development through picture book reading: Replication and extension of a videotape training format. Journal of Educational Psychology, 86, 235-243.

Bandura, A. (1997). Self-efficacy: The exercise of control. NY: Freeman.

Bishop, D. V. M., \& L. B. Leonard, L. B. (2000). Speech language impairments in children: Causes, characteristics, interventions, and outcomes. Hove, UK: Psychological Press.

Blank, M., Rose, S.A., \& Berlin, L.J. (1978). Preschool Language Assessment Instrument: The language of learning in practice. New York: Harcourt Brace Jovanovich.

Bus, A.G., van Ijzendoorn, M.H., \& Pellegrini, A.D. (1995). Joint book reading makes for success in learning to read: A meta-analysis on intergenerational transmission of literacy. Review of Educational Research, 65, 1-21.

Craig-Thoreson, C., \& Dale, P.S. (1999). Enhancing linguistic performance: Parents and teachers as book reading partners for children with language delays. Topics in Early Childhood Special Education, 19, 28-39.

Elley, W.B. (1989). Vocabulary acquisition from listening to stories. Reading Research Quarterly, 24, 174-187.

Fielding-Barnsley, R., \& Purdie, N. (2003). Early intervention in the home for children at risk of reading failure. Support for Learning, 18, 77-82.

Hanafin, J., \& Lynch, A. (2002). Peripheral voices: Parental involvement, social class and educational disadvantage. British Journal of Sociology of Education, 23, 3549. 
Hargrave , A.C., \& Sénéchal, M. (2000). A book reading intervention with preschool children who have limited vocabularies: The benefits of regular and dialogic reading. Early Childhood Research Quarterly, 15, 75-90.

Hay, I., Elias G., Homel R., Freiberg, K., Ernst R., \& Jensen H. (2003). Occurrence of language difficulties in children and the effectiveness of a language intervention program. In B. Bartlett, F. Bryer, \& D. Roebuck (Eds.), Reimagining Practice Researching Change (Vol 2, pp. 41-547). Brisbane, Griffith. University.

Homel, R., Elias, G., \& Hay, I. (2001). Developmental prevention in a disadvantaged community In J.Dixon \& G. Vimpani (Eds) Social origins of health and wellbeing (269-279). Cambridge: Cambridge University Press.

Hoover-Dempsey, K.V., \& Sandler, H.M. (1997). Why do parents become involved in their children's education? Review of Educational Research, 67, 3-42.

Kim, Y.S., \& Cole, K. N. (2002). Facilitating first language development in young Korean children through parent training in picture book interactions. Bilingual Research Journal, 26, 367-384.

Marvin, C.A., \& Wright, D. (1997). Literacy socialization in the homes of preschool children. Language, Speech and Hearing Services in Schools, 28,154-163.

Morgan, L., \& Goldstein, H. (2004). Teaching mothers of low socioeconomic status to use decontextualized language during storybook reading, Journal of Early Intervention, 26 235-252.

Newman, S.B., \& Celano, D. (2001). Access to print in low-income and middleincome communities: An ecological study of four neighborhoods. Reading Research Quarterly, 36, 6-26.

Raz, I.S., \& Bryant, P. (1990). Social background, phonological awareness and children’s reading. British Journal of Developmental Psychology, 8, 209-225.

Schiff-Myers, N.B., Djukic, J., McGovern-Lawler, J., \& Perez, D. (1993). Assessment considerations in the evaluation of second-language learners: Case study. Exceptional Children, 60, 237-249.

Sénéchal, M., Cornell, E.H., \& Broda, L.S. (1995). Age-related differences in the organization of parent-infant interactions during picture-book reading. Early Childhood Research Quarterly, 10, 317-337.

Snow, C.E., Burns, S., \& Griffin, P. (1998). Preventing reading difficulties in young children. Washington, DC: National Academy Press.

Teale, W.H., \& Sulzby, E. (1986). Emergent literacy: Writing and reading. Norwood, NJ: Ablex. 
Wasik, B.A., Bond, M.A., \& Hindman, A. (2002). Creating opportunities for discourse: Language and literacy development in economically disadvantaged children. In O.N. Saracho, \& B. Spodek (Eds.), Contemporary perspectives in literacy in early childhood education (pp. 53-76). Greenwich: IAP Pub.

Whitehurst, G.J., Arnold, D.S., Epstein, J.N., Angell, A.L., Smith, M., \& Fischel, J.E. (1994). A picture book reading book intervention in day care and home for children from low-income families. Developmental Psychology, 30, 679-689.

Whitehurst, G. J., \& Lonigan, C.J. (1988). Child development and emergent literacy. Child Development, 69, 848-872. 